\title{
Knowledge, Attitudes and Practices of Health Care Professionals on Ebola Virus Disease in Democratic Republic of the Congo
}

\author{
Kabemba Bukasa Héman ${ }^{1,2}$ \\ ${ }^{1}$ Department of Nursing Sciences, Higher Institute of Medical Techniques of Lubao, Lubao, Democratic Republic of Congo \\ ${ }^{2}$ Department of Nursing Sciences, Higher Institute of Medical Techniques of Kalemie, Kalemie, Democratic Republic of Congo \\ Email: hemanuska@gmail.com
}

How to cite this paper: Héman, K.B. (2019) Knowledge, Attitudes and Practices of Health Care Professionals on Ebola Virus Disease in Democratic Republic of the Congo. Open Access Library Journal, 6: e5504.

https://doi.org/10.4236/oalib.1105504

Received: May 27, 2019

Accepted: July 1, 2019

Published: July 4, 2019

Copyright $\odot 2019$ by author(s) and Open Access Library Inc.

This work is licensed under the Creative Commons Attribution International License (CC BY 4.0).

http://creativecommons.org/licenses/by/4.0/

\begin{abstract}
Background: Ebola virus disease (EVD) remains a public health problem. Health workers are constantly at risk of contracting the disease because of the high risk of infection. The Democratic Republic of Congo is in its tenth epidemic. Objective: This study aimed to determine the level of knowledge, attitudes and practices of care professionals about the occurrence of a possible outbreak of EVD. Methods: This was a prospective cross-sectional and descriptive survey of the care staff of the Moba administrative unit. The period from June to August 2018 was chosen. We administered an adapted CDC-2014 questionnaire to the health care providers in the targeted hospitals. Results: A total of 66 care professionals had participated in our survey. The means age of the respondents was $32 \pm 2.1$ years, with a male predominance $(57.6 \%)$ and a nurse $(75.8 \%)$. The majority of care professionals had good knowledge of the name and reservoir of the causal agent, the severity of the disease, the modes of prevention and the attitude to adopt in case of suspicion of Ebola virus disease, and the year of the last epidemic. On the other hand, the level of knowledge on the definition of the disease, the transmission routes, the virological and clinical aspects and even the number of epidemics that have already affected the Democratic Republic of Congo and the year of the first epidemic was insufficient. The majority of respondents $(78.8 \%$; $p<0.01)$ had never attended Ebola training. Conclusion: The level of knowledge of the care professionals was below expectations. Strengthening care professionals capacity on Ebola virus disease is imperatively required in a short time, given epidemic episodes.
\end{abstract}

\section{Subject Areas}

Infectious Diseases 


\section{Keywords}

Attitudes, Care, Ebola, Knowledge, DRC

\section{Introduction}

Ebola virus disease (EVD) is an acute, severe and often fatal haemorrhagic fever caused by a Filoviridae virus. There are five identified species of Ebola including Ebola zaire, Ebola sudan, Ebola bundibugyo, Ebola Tai Forest and Ebola reston (non-pathogenic for humans) [1] [2] [3] [4]. It occurs as an epidemic mainly in tropical environments [5] [6] [7], often in the countries of Central, West and South Africa [8] [9] [10]. The DRC experienced its first epidemic in 1976 and to date has counted to ten (including the second most deadly epidemic in the world, in the province of North Kivu and Ituri), from where it is considered the country where care staffs have greater experience with EVD [7] [11].

The epidemic of EVD has economic and socio-cultural consequences [3] [12]. The Ebola virus is highly contagious and lethal. The infection begins in primates such as monkeys, gorillas, and chimpanzees (epizootic) to be transmitted later in humans. The modes of propagation and of interpersonal diffusion require the contact with the bodily fluids of the patient or the corpse. Subsequently, general and hemorrhagic clinical signs such as fever, physical asthenia, jaundice, haematemesis and bloody diarrhea develop, followed by signs related to multiple visceral failure and death [3] [13].

As a result, ignorance at the epidemic alert threshold and the attitude to take in the suspect person may have consequences for the increase of suspected and contorted cases [2] [12] [14].

Health care workers are at risk because they work in a high-risk environment. In resource-poor countries, health infrastructure is under-equipped and low-skilled staffs are responding to an Ebola outbreak; this weakness of the health system is an element of vulnerability that impacts on lethality [15]. For Muyembe et al. [1], during the 1995 epidemic in Kikwit in the Democratic Republic of Congo, several cases of EVD were diagnosed with Shigellosis because of bloody diarrhea. It was not until the results of the CDC (Center for Disease Control and Prevention, Atlanta, USA) to confirm the diagnosis of EVD (at that time called Ebola or FHVE haemorrhagic fever). In this context, the assessment of the level of knowledge, attitudes and practices of care staff on EVD is important as it will measure the need for capacity building on prevention and the ability to respond to the epidemic of EVD.

Many authors have tackled studies on EVD, at various aspects and backgrounds of our study. In a Malian study [2], care staff had a good knowledge of the clinical signs and modes of transmission of the disease, but poor knowledge of the Ebola virus. Fasekas et al. [16] and Karolyhazy et al. [17] reported in England and Hungary, respectively, the knowledge deficits of junior doctors with 
regard to Ebola virus disease.

Boumandouki et al. [18] emphasize the role of the immediate entourage, such as the family, in the spread of the disease; and Behavior Change Communication (BCC) to prevent transmission of the Ebola virus. The assessment of knowledge of care staff remains a strategic tool for identifying the need for training [19]. There is little study oriented in the assessment of knowledge, attitudes and practices of care staff [8], hence our motivation to address this issue in order to assess the level of staff readiness a possible epidemic and the need for training on EVD.

\section{Materials and Methods}

\subsection{Site of the Study}

Our research was carried out in the Province of Tanganyika, territory and city (administrative branch) of Moba, bringing together five districts: Congo, Kirungu, Kinkalata, Katele and Regeza. The choice of this research environment was motivated by the fact that no epidemic of EVD has ever occurred.

In view of our research topic, we had submitted a questionnaire to the health care staff (Rapid Training Officers, Nurses, Doctors) of five public health structures (Reference Health Center of Katele, Health Centers of Kasama, Katombe, General Reference Hospital of Moba/Kirungu) and two private medical centers (MAMAN Zamuda Medical Center and Polyclinic "La Bénédiction"). The choice of these hospital structures has no direct relationship with the EVD. It takes into account their high capacity and a large number of care staff, in an environment where it is difficult to accurately determine at the central office of the health zone the exact number of nurses and structures of care that operates.

\subsection{Type and Period of Study}

It was a descriptive cross-sectional study that covers the three-month period from June to August 2018. The use of the questionnaire allowed the data to be collected.

\subsection{Study Population}

- Target population: Care staff (rapid training agent or auxiliary caregivers, nurses, doctors).

- Sample: Our sample, comprehensive and systematic, was 66 health care staff who met the inclusion criteria.

\subsection{Inclusion Criteria}

All care staff (Rapid Training Officer, Nurses, Physicians) working in the target structures and having agreed to answer our questionnaire on the day of the planned visit to the health facility, in relation to the study period. Any staff who did not meet these requirements had been excluded. 


\subsection{Study Parameters}

The parameters studied in this study included:

- Characteristics of care staff (age, sex, level of education, seniority in the profession, training on EVD);

- Knowledge about EVD: Based on the CDC-2014 questionnaire that we adapted in our context. The following elements were sought: 1) The definition of MV; 2) Causal agent (name, nucleic acid, number and types of species, product that inactivates it, origin of the term Ebola, reservoir of virus, other similar viruses causing haemorrhagic fevers); 3) Routes of contamination; 4) Symptoms and signs of suspicion; 5) Modes of prevention and attitudes in a suspect patient; 6) Severity (yes or no); 7) Number of known epidemics in the DRC and the years of the first and last epidemic.

\subsection{Conduct of the Investigation}

After obtaining the authorization to conduct the research (Moba Health Zone), we developed a questionnaire to be submitted to the care staff. When we went down to the field of investigation, we gave the questionnaire to the person to be investigated and the person answered in our presence, without consulting the Internet or the book. When compiling the results, the knowledge of the care staff was judged in three categories:

- Good: complete and truthful answer;

- Wrong: incomplete response or containing false elements;

- Do not know: no idea about the question asked.

\subsection{Statistical Analysis Methods}

The data from our survey were compiled to produce the tables and figures

(Figure $1 \&$ Figure 2). We used the calculation of frequency, mean and standard

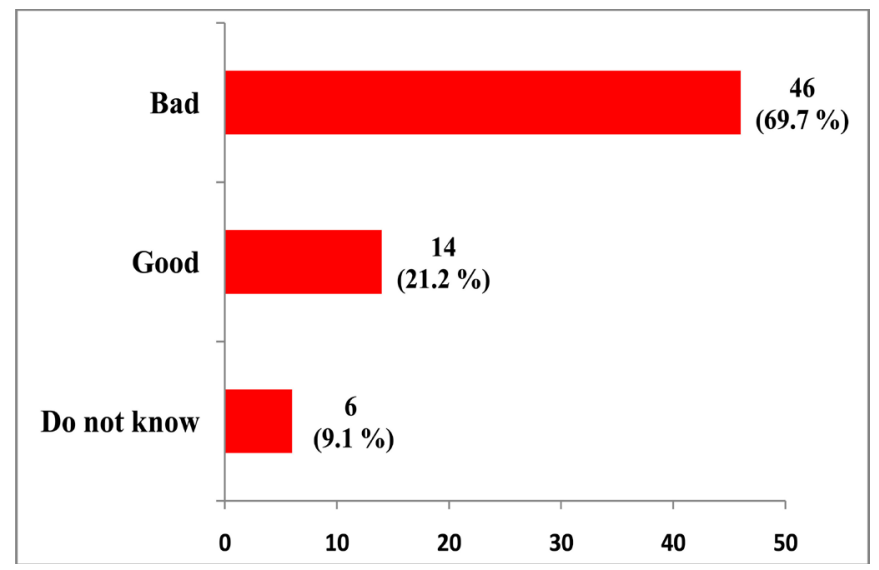

${ }^{*}$ Fever was the most cited symptom. The response was considered good if the respondent could identify at least seven signs and symptoms related to the Ebola virus disease. On the other hand, it was judged to be bad or incomplete in case the respondents had cited the signs and symptoms unrelated to the Ebola virus disease, sometimes mixing the true and the false.

Figure 1. The knowledge of evocative signs and symptoms of EVD $(\mathrm{p}<0.01)$. 


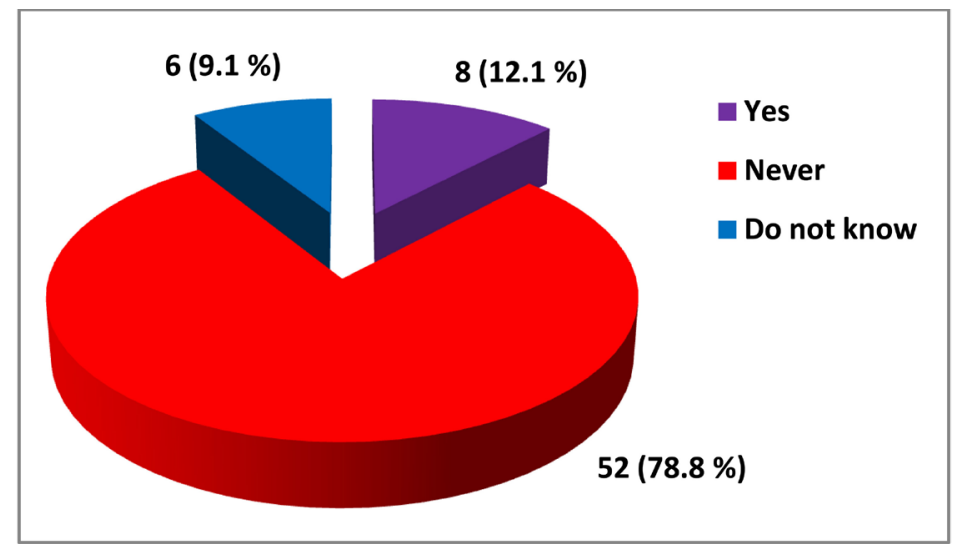

Figure 2. Ebola virus disease training $(\mathrm{p}<0.01)$.

deviation. The chi-square test of Person with a threshold $\mathrm{p} \leq 0.05$ was used.

\section{Results}

Seventy-six care staff had withdrawn the survey questionnaires. The proportion of respondents was $66 \%$, or $86.8 \%$.

With respect to the results of our investigation among the 66 health care staff in Moba, the socio-demographic characteristics showed that $57.6 \%(n=38)$ were men, while $42.4 \%(n=28)$ were women; the age group 18 to 27 was the most represented at $33.3 \%(n=22 / 66)$ followed by 58 to 60 at $18.2 \%(n=12)$; A2 nurses were most met with $33.3 \%$ followed by A1 (27.3\%).

General practitioners accounted for $9.1 \%$, or 6 cases. In the majority of cases, the surveyed staff had already completed more than one year in the profession. The mean age was $32 \pm 2.1$ years old (Table 1 ).

For this survey on Ebola, the majority of respondents knew the name of the causal agent $(n=52,78.8 \%)$, the reservoir of the virus $(n=50,75.8 \%)$, methods of prevention $(n=40,60.6 \%)$, the attitude to be adopted in case of suspicion of $\operatorname{EVD}(n=48,72.7 \%)$, the year of the last epidemic $(n=5481.8 \%)$ and the disease was severe ( $n=60,90.9 \%$ ) (Tables $2-4)$. On the other hand, the definition of the Ebola virus disease was known only in 30 respondents, i.e. $45.5 \%$. Virological knowledge was inadequate or inadequate (Table 2), as were the number of epidemics in the DRC and the year of the first Ebola outbreak (Table 3).

\section{Discussion}

In many countries, especially in the developing countries, vector-borne diseases are a public health problem facing the health systems in place. In this group of vector-borne diseases, the share of viruses such as Chikungunya virus, dengue virus, West Nile virus, Cassa virus, yellow fever virus and Ebola virus is not negligible [2] [19]. It has become one of the deadliest viruses in recent years since the outbreak of the epidemic in Southern Sudan (Nzara) and the DRC (Yambuku) [1] [10] [17]. In this context, the need to assess the level of knowledge of health care workers about Ebola is extremely important in the context of hospital-based prevention 
Table 1. Sociodemographic characteristics of the respondents $(n=33)$.

\begin{tabular}{|c|c|c|}
\hline Characteristics & $\mathbf{n}$ & $\%$ \\
\hline \multicolumn{3}{|l|}{ Sex } \\
\hline Male & 38 & 57.6 \\
\hline Female & 28 & 42.4 \\
\hline \multicolumn{3}{|l|}{ Age (years) } \\
\hline $18-27$ & 22 & 33.3 \\
\hline $28-37$ & 8 & 12.1 \\
\hline $38-47$ & 8 & 12.1 \\
\hline $48-57$ & 10 & 15.2 \\
\hline$\geq 58$ & 12 & 18.2 \\
\hline \multicolumn{3}{|l|}{ Level of study } \\
\hline \multicolumn{3}{|l|}{ Nurses } \\
\hline A0 & - & - \\
\hline $\mathrm{A} 1$ & 18 & 27.3 \\
\hline $\mathrm{A} 2$ & 22 & 33.3 \\
\hline $\mathrm{A} 3$ & 10 & 15.1 \\
\hline $\mathrm{RT}^{*}$ & 10 & 15.1 \\
\hline Doctors (general practitioners) & 6 & 9.1 \\
\hline \multicolumn{3}{|l|}{ Seniority (years) } \\
\hline$<1$ & 6 & 9.1 \\
\hline $1-4$ & 16 & 24.2 \\
\hline $5-10$ & 16 & 24.2 \\
\hline $15-20$ & 8 & 12.1 \\
\hline $25-30$ & 6 & 9.1 \\
\hline Not reported & 14 & 21.2 \\
\hline
\end{tabular}

${ }^{*}$ Rapid Training or Auxiliary Care Agent; A3: Patent of Medical Humanities; A2: Diploma of the Medical Humanities; A1: Bachelor +3 years in Nursing; A0: Bachelor +5 years in nursing sciences.

Table 2. Mastery of the definition of EVD and the causal agent.

\begin{tabular}{lccc}
\hline \multicolumn{1}{c}{ Criteria $(\mathrm{n}=66)$} & \multicolumn{3}{c}{ Answer } \\
\cline { 2 - 4 } & Good $^{*}$ & Bad $^{* *}$ & Do not know \\
\hline Definition of EVD & $30(45.5)$ & $28(42.4)$ & $8(12.1)$ \\
Name of the causal agent & $52(78.8)^{\ddagger}$ & - & $14(21.2)$ \\
The nucleic acid of the causative agent & $24(36.6)$ & $2(3.0)$ & $40(60.6)$ \\
Species known to the causative agent & $10(15.2)$ & $14(21.2)$ & $42(63.6)$ \\
Products that inactivate the causative agent & $8(12.1)$ & $4(6.1)$ & $54(81.8)$ \\
Where does the term Ebola come from? & $24(36.4)$ & $12(18.2)$ & $30(45.5)$ \\
Routes of Contamination & $8(12.1)$ & $44(66.7)$ & $14(21.2)$ \\
Reservoir of the causative agent & $50(75.8)^{\ddagger}$ & $6(9.1)$ & $10(15.2)$ \\
Other viruses at risk for infectious diseases such as EVD & $26(39.4)$ & $4(6.1)$ & $36(54.5)$ \\
\hline
\end{tabular}

${ }^{\star}$ Complete; ${ }^{* *}$ Incomplete; ${ }^{* *}$ Respondents should give at least 3 agents or products; ${ }^{*} \mathrm{p}<0.01$. 
Table 3. Epidemiology of EVD in the DRC.

\begin{tabular}{lccc}
\hline \multirow{2}{*}{ Criteria } & \multicolumn{3}{c}{ Response } \\
\cline { 2 - 4 } & Good & Bad & Do not know \\
\hline Number of epidemics on behalf of the DRC & $18(27.3)$ & $36(54.5)^{*}$ & $12(18.2)$ \\
The year of the last epidemic in the DRC & $54(81.8)^{* *}$ & $8(12.1)$ & $4(6.1)$ \\
Year of the first epidemic in the DRC & $8(12.1)$ & $48(72.7)^{* *}$ & $10(15.2)$ \\
\hline
\end{tabular}

${ }^{*} \mathrm{p}>0.05 ;{ }^{* *} \mathrm{p}<0.05$.

Table 4. Severity of the disease, prevention methods and attitude to adopt in case of suspicion of EVD.

\begin{tabular}{lccc}
\hline \multirow{2}{*}{ Criteria $(\mathbf{n}=66)$} & \multicolumn{3}{c}{ Response } \\
\cline { 2 - 4 } & Good & Bad & Do not know \\
\hline Knowledge about severity of EVD? & $60(90.9)^{\star}$ & - & $6(9.1)$ \\
Knowledge of preventions methods & $40(60.6)^{*}$ & $10(15.2)$ & $16(24.2)$ \\
Attitude to adopt in case of suspicion of EVD & $48(72.7)^{*}$ & $4(6.1)$ & $14(21.2)$ \\
\hline
\end{tabular}

${ }^{*} \mathrm{p}<0.05$.

and care. The results of this evaluation should enable decision-makers, politico-administrative authorities, to highlight the means necessary to meet the training requirements of the staff and to have the necessary equipment to deal with any eventual outbreak declaration. The province of Tanganyika has never experienced EVD cases (e.g. EBOLA fever) but no region of the world is safe in the $21^{\text {st }}$ century when globalization makes the world's land a global village. Microbes take advantage of this to spread. So the risk exists everywhere. It is in this context that this study was initiated, with the aim of assessing the diagnostic and response capacities of health care personnel on the EVD in Moba, in the South of the Democratic Republic of Congo.

We surveyed the health care staff in Moba, out of a total of sixty-six agents, predominantly male $(57.6 \%)$, with a mean age of $32 \pm 2.1$ years, mostly nurses (mostly A2) and having a very large proportion of more than one year of professional experience.

The evaluation of the nursing staff on the EVD followed a precise pattern: definition, causative agent (name, nucleic acid, number of species, routes of contamination, origin of the term Ebola, reservoir of the virus, product which inactivates the causative agent), symptoms, prevention methods, severity, history of training on the survey topic, number of epidemics recorded in the DRC (number, year of first epidemic and last epidemic), other haemorrhagic fevers and attitudes or behavior to take in case of suspicion of EVD. At the end of our survey, the overall level of knowledge is not satisfactory and staffs are not prepared to deal with an EVD outbreak.

For Sodano L. in 2015 [20], the parameters evaluated must reach seventy percent to be considered correct. This is not generally the case for several parame- 
ters evaluated in this series of studies.

For this first study in the province of Tanganyika, the health care workers surveyed had good knowledge of the severity of the disease, the attitude to be taken in case of suspicion of the EVD, the methods of prevention, the year of the last epidemic (which may be justified by the fact that the study was conducted during the last two outbreaks in the DRC), the name and reservoir of the causative agent. As Togola et al. in Mali [2], the health care workers we interviewed had low and poor levels of virological knowledge. Unlike the Malian study and ours, the care staffs do not control the majority of the signs and symptoms of suspicion and the pathways of contaminations. The lack of mobilization to the level of the danger which lurks us and the significant absence of the training in favor of the caring personnel would be at the base.

Health service providers are expected to have an adequate level of knowledge to prevent and care for patients. This knowledge ranges from history to treatment, including virological, clinical and paraclinical aspects [19]. Ebola virus disease (from the Ebola River near Yambuku village in the DRC) is an acute and severe viral infection caused by the Ebola virus, discovered in 1976 by the Belgian Peter Piot. The latter, ribonucleic acid virus (RNA), has five species: Ebola of the forest of Taï in Ivory Coast, Ebolareston, Ebola bundibugyo, Ebola sudan and Ebola zaïre. Until these days, it is Ebola zaire who is the most murderous [19]. The Ebola virus is fragile but highly pathogenic, with mortality of the order of $25 \%$ to $90 \%$. It does not survive in outdoor environments and is destroyed by heat (30 - 60 minutes at 60 degrees Celsius), ultraviolet and gamma rays, solvents such as Ether and Betapropriolactone. Bleach, soap, detergent, formalin and boiling for at least five minutes inactivate it [2] [20] [21].

It has been reported that Ebola reaches humans after close contact with the blood, secretions, organs or body fluids of infected animals such as monkeys (chimpanzees, gorillas), wood antelopes, and porcupines sick or dead. The initial human contaminations are most often due to direct contact with animals (by preparing or consuming monkey meat), which live in the environment of fruit-eating bats of the family Pteropodidae, which are the natural hosts Ebola virus [6] [16] [17]. The Ebola virus then spreads secondarily through human-to-human transmission following direct contact with the injured skin or mucous membranes with blood, secretions, organs or body fluids of infected persons, or with surfaces or materials (eg example bed linen, clothing) that have been contaminated by these liquids. EVD is transmitted by close interfamilial and inter-hospital contacts: it is therefore a nosocomial disease that requires extreme biosecurity measures. Transmission during funeral rites plays an important role, especially in Africa: contact with corpses exposes them to a very high risk of contamination because it is usual for bodies to remain exposed for several days, receiving the visit and "undergoing" embraces of all the relatives of the deceased [11] [18]. The contacts can also be infected after contact with the sweat of a terminally ill patient in case of skin lesion and especially by indirect mucosal 
contamination (contact with the nasal or ocular mucosa with the hands). Transmission via the respiratory and/or airborne route is virtually excluded, whereas the risk of sexual transmission has been mentioned and is under study [21] [22]. Hence the precautions required by the Ebola survivor care staff: all sexual relations should be protected.

The virus infects the endothelial system, on average three days, and then spreads rapidly to the entire body by suppressing the immune system. It is therefore a systemic disease. After an incubation period, which varies from 3 to 21 days, the patients present productive and susceptible signs of the disease: fever, jaundice, nausea and vomiting, fatigue, abdominal pain, anorexia, headache, dyspnea, hiccups, phlyctenes, etc. At the state stage occurs a hemorrhagic syndrome (epistaxis, petechiae, melena, hematuria, bloody diarrhea and gingivorragia) and multiorgan failure [3] [23]. But in 2000, Leroy et al. [24] reported that in $45.8 \%$ individuals are asymptomatic.

Most of the diagnostic confirmation requires the use of molecular biology and serological tests: PCR (RT-PCR), which detects viral RNAs in the blood or tissues in the acute phase, and sequencing allows the typing of viral strains; ELISA: detects the antigen circulating in the blood or present in the necropsy parts; electron microscopy: detects virus in tissues, biological specimens and isolates in cell culture; and serology by specific IgM capture and IgG ELISA assays and tests using inactivated viral antigens [2] [19].

The curative treatment does not exist (recourse to the symptomatic treatment) and to the study, the preventive measures and the required attitudes remain the following ones, that all personnel of care and supposed to control: to notify the hierarchy; quickly quarantine animals suspected of being infected and then bury or incinerate them immediately; wear gloves and other protective clothing to handle all animals and their excrement; thoroughly cook the product from the animals before eating it; adapt funeral sites without danger; have a safe injection method; wash hands frequently with soap; identify infected and isolated persons; to circumscribe the affected areas by prohibiting the increased circulation of populations; look for people who have been in contact with suspected or proven cases of EVD.

The DRC has already been affected by ten epidemics of the Ebola virus disease. Only provinces in the southern part of the country remain unaffected. The months from May to December are the most concerned:

- First: August 1976 (Yambuku, Mongala Province) [11] [16];

- Second: June 1977 (Tandale, South Ubangi Province) [11];

- Third: May-July 1995 (Kikwit, Kwilu province) [1] [11];

- Fourth: August-November 2007 (Mweka, Kasai province) [11];

- Fifth: December 2008-February 2009 (Mweka, Kasai province) [11];

- Sixth: June to November 2012 (Isiro locality, Haut-Uélé province) [11] [23];

- Seventh: August-November 2014 (Boende, Equateur Province) [5] [11];

- Eighth: May-July 2017 (Likati, Bas-Uélé province) [7]; 
- Ninth: April-July 2018 (Bikoro, Equateur Province) [7];

- Tenth: August 2018 (North Kivu province and Ituri): the most deadly in the DRC and second in the world by mortality.

In the great and deadly outbreak of West Africa in 2014, which began with Guinea to reach Liberia and Sierra Leone, and the last two epidemics in the DRC [7] [10] [11], prototypes of vaccines and drugs were officially used: rVSVSV-ZEBOV vaccine from the American pharmaceutical group "Merck and Co." [25] [26]; the mAb114a stemming from the research of Congolese Jean-Jacques Muyembe of the National Institute of Biomedical Research, "INRB" in acronym, on the serum of a survivor of the EVD epidemic of 1995 in Kikwit [27]; ZMapp of the American firm "Mapp Biopharmaceutical” [28] [29]; Remdesivir of the American firm Gilead Sciences; Regn 3435-3471-3479 from the American firm "Regeneron Pharmaceuticals"; and Favipiravir (T-705 or organofluorine pyrazine) from the Japanese company Toyama Chemical [30] [31].

In a recent Beninese study, 2018 by Oritsemofe et al. [32] the respondents had an overall knowledge of $92.8 \%$ among health workers who seemed to master the EVD well that our surveyed population in Moba (especially in terms of transmission and symptoms). For Etokidem et al. in Nigeria in 2018 [6] among nursing students, the knowledge on the EVD was mainly: natural reservoir known by about $68 \%$, mode of direct contamination with blood or body fluids of an infected person known in $71.8 \%$, the origin of the word EBOLA known in $65.5 \%$, but only $40.1 \%$ who knew the year of appearance (i.e. 1976).

In a country where the disease has been discovered and has had the highest number of EVD epidemics, our level of knowledge is insufficient and is a call to any health science worker for capacity building sessions. This is what several studies conclude [9] [13] [16] [17]. Only satisfactory or correct knowledge in favor of health workers can facilitate monitoring the occurrence of EVD and initiating the response. If not, the task would be very complex and difficult. We believe that the results of this study may be applicable to all health care facilities in the Democratic Republic of the Congo.

\section{Conclusions}

From 1976 to the present day, the Democratic Republic of Congo has been the victim of ten epidemics of the Ebola virus disease (formerly called Ebola haemorrhagic fever: FHVE) in the north, center and east of the country respectively. There remains the South which reunites the four dismembered provinces of the former Katanga (Haut-Katanga, Lualaba, Haut-Lomami and Tanganyika). Contrary to our original hypothesis, this study found that health care workers have inadequate levels of knowledge to cope with a possible outbreak of Ebola. There is an urgent need for training of health care workers, health education and social mobilization for the whole population.

Therefore, before closing this study, the results obtained push us to formulate the following recommendations: 
- Health workers: to be ready to respond to any EVD outbreak; organize a presentation theme on the epidemic that is underway (DRC); to follow the news on the scientific and epidemiological evolution of Ebola Virus and EVD;

- Political, Administrative and Health Authorities: ensure the continuous training of health workers; encourage researchers to conduct in-depth research on EVD;

- Healthcare structures: advocate with health authorities in the country to be trained on EVD; create a training session by department;

- Other researchers: carry out similar studies and address the scientific aspects that we have not taken into account.

\section{Acknowledgements}

We would like to thank Suzane Kyambulu Véronique for his contributions in data collection.

\section{Conflicts of Interest}

No conflict of interest related to this study was recorded.

\section{References}

[1] Muyembe-Tamfum, J.J., Kipasa, M., Kyungu, C. and Colebunders, R. (1999) Ebola Outbreak in Kikwuit, Democratique Republic of the Congo: Discovery and Control Measures. The Journal of Infectious Diseases, 179, S259-S262. https://doi.org/10.1086/514302

[2] Togola, A.K. and Maiga, A.I. (2016) Perception du personnel soignant du CHU Gabriel Touré sur la maladie à virus Ebola (Mali). Editions Universitaires Européennes, ebook, $96 \mathrm{p}$.

[3] Goeijenbier, M., Van Kampen, J.J.V., Reusken, C.B.M., Koopmans, M.P.G. and Van Gorp, E.C.M. (2014) Ebola Virus Disease: A Review on Epidemiology, Symptoms, Treatment and Pathogenesis. The Journal of Medicine, 72, 442-449.

[4] Chowell, G. and Nishiura, H. (2014) Transmission Dynamics and Control of Ebola Virus Disease (EVD): A Review. BMC Medicine, 12, 196. https://doi.org/10.1186/s12916-014-0196-0

[5] Maganga, G., Kapetski, J., Berthet, N., Kebela Ilunga, B., Kabange, F., Mbala Kingebeni, P., et al. (2014) Ebola Virus Disease in the Democratic Republic of Congo. The New England Journal of Medicine, 371, 2083-2091. https://doi.org/10.1056/NEJMoa1411099

[6] Etokidem Aniekan, J., Ago Boniface, U., Mary, M., Affiong, E., Eno, U. and Anastasia, I. (2018) Ebola Virus Disease: Assessment of Knowledge, Attitude and Practice of Nursing Students of a Nigerian University. African Health Sciences, 18, 256-267. https://doi.org/10.4314/ahs.v18i1.9

[7] Barry, A., Ahuka-Mundeke, S., Ali Ahmed, Y., Allaranger, Y., Anoko, J., Nicolas Archer, B., et al. (2018) Outbreak of Ebola Virus Disease in the Democratic Republic of the Congo, April-May 2018: An Epidemiological Study. The Lancet, 392, 213-221. https://doi.org/10.1016/S0140-6736(18)31387-4

[8] Nickerson, J. (2014) Réagir au vrus Ebola: Rôle des revues médicales pendant les 
urgences mondiales de santé publique. Canadian Journal of Respiratory Therapy, 50, 71-72.

[9] Attinsounon, C.A.S., Hounnankan, C.A., Dovonou, C.A., Alassani, C.A. and Salifou, S. (2017) Connaissances et attitudes des relais communautaires sur les fievres hemorragiques à virus Lassa et Ebola dans le departement de la Donga (Nord Benin). Pan African Medical Journal, 26, 229. https://doi.org/10.11604/pamj.2017.26.229.12072

[10] Wang, Y., Li, J., Hu, Y., Liang, Q., Wei, M. and Zhu, F. (2017) Ebola Vaccines in Clinical Trial: The Promising Candidates. Human Vaccines \& Immunotherapeutics, 13, 153-168. https://doi.org/10.1080/21645515.2016.1225637

[11] Roselo, A., Mossoko, M., Flasche, S., Van Hoek, A.J., Mbala, P., Camacho, A., et al. (2015) Ebola Virus Disease in the Democratic Republic of the Congo, 1976-2014. ELife, 4, e09015. https://doi.org/10.7554/eLife.09015

[12] Gatiso, T.T., Ordaz-Nemeth, I., Grimes, T., Lormie, M., Tweh, C., Kuhl, H.S., et al. (2018) The Impact of the Ebola Virus Disease (EVD) Epidemic on Agricultural Production and Livelihoods in Liberia. PLoS Neglected Tropical Diseases, 12, e0006580. https://doi.org/10.1371/journal.pntd.0006580

[13] Hisam, A., Rana, M.N. and Rahman, M. (2016) Knowledge and Attitude Regarding Ebola Virus Disease among Medical Students of Rawalpindi: A Preventable Threat Not Yet Confronted. Pakistan Journal of Medical Sciences, 32, 1015-1019. https://doi.org/10.12669/pjms.324.9898

[14] Nettey, O.E.A., Enuameh, Y.A., Zandoh, C., Anane, E.A., Abukari, M., Agbokey, F., et al. (2016) Knowledge, Attitudes and Preventive Practices on Ebola Virus Disease in the Kintampo Districts of Ghana. Health, 8, 1465-1484.

https://doi.org/10.4236/health.2016.814146

[15] Kalra, S., Kelkar, D., Galwenkar, S.C., Papadimos, T.J., Stawicki, S.P., Arguilla, B., et al. (2014) The Emergence of Ebola as a Global Health Security Threat: From Lessons Learned to Coordinated Multilateral Containment Efforts. Journal of Global Infectious Diseases, 6, 164-177. https://doi.org/10.4103/0974-777X.145247

[16] Faseka, B., Fasekas, J., Moledina, M., Fasekas, B. and Karolyhazy, K. (2015) Ebola Virus Disease: Awareness among Junior Doctors in England. Journal of Hospital Infection, 90, 260-262. https://doi.org/10.1016/j.jhin.2015.03.007

[17] Karolyhazy, K., Fasekas, B., Fasekas, J., Hermann, P. and Marton, K. (2016) Ebola Virus Disease: Awareness among Dental Student in Hungry. Acta Microbiologica et Immunologica Hungarica, 63, 325-337. https://doi.org/10.1556/030.63.2016.003

[18] Boumandouki, P., Furmenty, P., Epelboin, A., Campbell, P. and Allarangar, V. (2005) Prise en charge des maladies et des défunts lors de l'épidémie de la fièvre hémorragique due au virus Ebola d'Octobre à Décembre 2003. Bulletin de la Société de Pathologie Exotique, 98, 218-223.

[19] Georges, A.J., Baize, S., Leroy, E.M. and Georges-Combot, M.C. (1998) Ebola Virus: What the Practitioner Needs to Know. Medecine Tropicale, 85, 177-186.

[20] Sodano, L., Radici, F., Rossini, A. and D’Alessandro, D. (2015) Cross Sectional Study on Knowledge of Health Care Workers about Ebola Virus Disease and Its Prevention: A Pilot Study in Two Hospitals in Rome (Italy). Annali di igiene: Medicina preventiva e di comunità, 27, 814-823.

[21] Lawrence, P., Danet, N., Reynard, O., Volchkova, V. and Volchkov, V. (2017) Human Transmission of Ebola Virus. Current Opinion Virology, 22, 51-58.

https://doi.org/10.1016/j.coviro.2016.11.013

[22] Kondé, M.K., Diop, M.K., Curtis, M.Y., Barry, A., Kouyaté, S., Ghilardi, L., et al. 
(2017) Sex Practices and Awareness of Ebola Virus Disease among Male Survivors and Their Partners in Guinea. BMJ Global Health, 2, e000412. https://doi.org/10.1136/bmjgh-2017-000412

[23] Kratz, T., Roddy, P., Tshomba Oldma, A., Jeffs, B., Pou Ciruelo, D., De La Costa, O., et al. (2015) Ebola Virus Disease Outbreak in Isiro Democratic Republic of the Congo, 2012: Signs and Symptoms, Managements and Outcomes. PLoS ONE, 10, e0129333. https://doi.org/10.1371/journal.pone.0129333

[24] Leroy, E.M., Baize, S., Volchkov, V.E., Fisher-Hoch, S.P., Georges-Courbot, M.C., Lansoud-Soukate, J., et al. (2000) Human Asymptomatic Ebola Infection and Strong Inflammatory Disease. The Lancet, 355, 2210-2215. https://doi.org/10.1016/S0140-6736(00)02405-3

[25] Gsell, P.S., Camacho, A., Kucharski, A.J., Watson, C., Bagayoko, A., Nadlaou, S.D., et al. (2017) Ring Vaccination with rVSV-ZEBOV under Expanded Access in Reponse to an Outbrek of Ebola Virus Disease in Guinea, 2016: An Operational and Vaccine Safety Report. The Lancet Infectious Diseases, 17, 1276-1284. https://doi.org/10.1016/S1473-3099(17)30541-8

[26] Henao-Restrepo, A.M., Camacho, A., Longini, I.M., Watson, C.H., Edmunds, W.J., Egger, M., et al. (2017) Efficacy and Effectiveness of an rVSV-Vectored Vaccine in Preventing Ebola Virus Disease: Final Resultats from the Guinea Ring Vaccination, Open-Label, Cluster-Randomised Trial (Ebola Ça Suffit!). The Lancet, 389, 505-518. https://doi.org/10.1016/S0140-6736(16)32621-6

[27] Misasi, J., Gilman, M.S., Kanekiyo, M., Gui, M., Cagigi, A., Malangu, S., et al. (2016) Structural and Molecular Basis for Ebola Virus Neutralization by Protective Human Antibodies. Science, 351, 1343-1346. https://doi.org/10.1126/science.aad6117

[28] Tran Erin, E.H., Nelson Elisabeth, A., Bonagiri, P., Simmons James, A., Shoemaker Charles, J. and Schmaljohn Connie, S. (2016) Mapping of Ebola Virus Neutralization by Monoclonal Antibodies in the ZMapp Cocktail Using Cryo-Electron Tomography and Studies of Cellular Entry. Journal of Virology, 90, 7618-7627.

https://doi.org/10.1128/JVI.00406-16

[29] Jacob, S.T. and Fletcher, T.E. (2017) Trial of ZMapp for Ebola Virus Infection. The New England Journal of Medicine, 376, 700-701.

https://doi.org/10.1056/NEJMc1614625

[30] Guedy, J., Piorkowski, G., Jacquot, F., Madelain, V., Nguyen, T.H.T., Rodallec, A., et al. (2018) Antiviral Efficacy of Favipiravir against Ebola Virus: A Translational Study in Cynomolgus Macaques. PLoS Medicine, 15, e1002535.

https://doi.org/10.1371/journal.pmed.1002535

[31] Furuta, Y., Komeno, T. and Nakamura, T. (2017) Favipiravir (T-705), a Broad Spectrum Inhibitor of Viral RNA Polymerase. Proceedings of the Japan Academy, Ser. B, Physical and Biological Sciences, 93, 449-4463.

[32] Oritsemofe Onowhakpor, A., Yakubu Adam, V., Ewomazino Sakpa, O. and Ukamaka Ozokwelu, L. (2018) Status of Ebola Virus Disease (EVD) Preventive Practices among Health Care Workers (HCWs) in Benin City: A Year after Disease Containment in Nigeria. Pan African Medical Journal, 30, 50. https://doi.org/10.11604/pamj.2018.30.50.15594 